\title{
Photochemical Acclimation of Three Contrasting Species to Different Light Levels: Implications for Optimizing Supplemental Lighting
}

\author{
Shuyang Zhen ${ }^{1}$ and Marc W. van Iersel \\ Department of Horticulture, University of Georgia, 1111 Miller Plant Science Building, Athens, GA \\ 30602
}

\begin{abstract}
ADDitional INDEX wORDs. electron transport rate, light acclimation, nonphotochemical quenching, photosynthesis, quantum yield of photosystem II, shade

Abstract. Photosynthetic responses to light are dependent on light intensity, vary among species, and can be affected by acclimation to different light environments (e.g., light intensity, spectrum, and photoperiod). Understanding how these factors affect photochemistry is important for improving supplemental lighting efficiency in controlledenvironment agriculture. We used chlorophyll fluorescence to determine photochemical light response curves of three horticultural crops with contrasting light requirements [sweetpotato (Ipomea batatas), lettuce (Lactuca sativa), and pothos (Epipremnum aureum)]. We also quantified how these responses were affected by acclimation to three shading treatments-full sun, $44 \%$ shade, and $75 \%$ shade. The quantum yield of photosystem II ( $\left.\Phi_{P S I I}\right)$, a measure of photochemical efficiency, decreased exponentially with increasing photosynthetic photon flux $(P P F)$ in all three species. By contrast, linear electron transport rate (ETR) increased asymptotically with increasing $P P F$. Within each shading level, the high-light-adapted species sweetpotato used high light more efficiently for electron transport than light-intermediate lettuce and shade-tolerant pothos. Within a species, plants acclimated to high light (full sun) tended to have higher $\Phi_{P S I}$ and $E T R$ than those acclimated to low light (44\% or $75 \%$ shade). Nonphotochemical quenching (NPQ) (an indicator of the amount of absorbed light energy that is dissipated as heat) was upregulated with increasing $P P F$; faster upregulation was observed in pothos as well as in plants grown under $75 \%$ shade. Our results have implications for supplemental lighting: supplemental light is used more efficiently and results in a greater increase in ETR when provided at low ambient $P P F$. In addition, high-light-adapted crops and crops grown under relatively high ambient light can use supplemental light more efficiently than low-light-adapted crops or those grown under low ambient light.
\end{abstract}

Low light often limits photosynthesis and growth and reduces plant quality and is the main limiting factor for the production of horticultural crops, such as vegetables and ornamental bedding plants, during the winter in temperate climates (Gaudreau and Chartbonneau, 1994; Lopez and Runkle, 2008; Nelson, 2012). Daily light integral [DLI (total $P P F$ integrated over 24-h)] in greenhouses in the northern latitudes of the United States can be as low as $2.5-10 \mathrm{~mol} \cdot \mathrm{m}^{-2} \cdot \mathrm{d}^{-1}$ from November to February (Korczynski et al., 2002). Supplemental lighting is often needed to produce high-quality crops in controlled-environment agriculture but can substantially increase production costs. For example, van Iersel and Gianino (2017) estimated that the cost of supplemental lighting provided by high-pressure sodium lamps can account for about $30 \%$ of the farm gate value for vegetable greenhouses. The high cost of supplemental lighting in controlled environments necessitates the need for more efficient use of supplemental light.

Supplemental light use efficiency can be improved by implementing energy-efficient lights, such as light-emitting diodes (LEDs) (Nelson and Bugbee, 2014). In addition to the

Received for publication 14 June 2017. Accepted for publication 11 July 2017. We thank the Fred C. Gloeckner Foundation, American Floral Endowment, and Georgia Research Alliance for financial support for this research. This work was also supported by the USDA National Institute of Food and Agriculture, Hatch project 1011550 .

We thank Robert Teskey and Paul Thomas for providing feedback on this article. We thank Sue Dove for technical support.

${ }^{1}$ Corresponding author. E-mail: syzhen@uga.edu. efficiency of the lights, the overall efficiency at which the electrical energy is converted into plant biomass depends on how efficiently plants use light for photosynthesis. Not all the light absorbed by plants is used in the photochemical reactions of photosynthesis. Some of the absorbed light is dissipated as heat and a small fraction is re-emitted as chlorophyll fluorescence (Maxwell and Johnson, 2000). The quantum yield of photosystem II, the efficiency with which photosystem II (PSII) uses absorbed photons for electron transport, or the moles of electrons transported per mole of photons (typically expressed as a unitless fraction) can be easily measured using chlorophyll fluorescence (Genty et al., 1989; Maxwell and Johnson, 2000). In addition, chlorophyll fluorescence can be used to estimate the ETR, which is often closely correlated with photosynthetic rate (Beer et al., 1998; Flexas et al., 1999), and the degree of heat dissipation under various light conditions. As light intensity increases, plants use the absorbed light less efficiently for photosynthesis, while more of that absorbed light energy is dissipated as heat or through chlorophyll fluorescence (Baker, 2008; Demmig-Adams et al., 1996; van Iersel et al., 2016b). As a result, supplemental light provided at high intensities or in addition to a high ambient light intensity is expected to be used relatively inefficiently for photosynthesis (van Iersel and Gianino, 2017) and presumably growth. Clearly, it is not beneficial to provide supplemental light when plants cannot use that light efficiently for photosynthesis.

Genetic adaptation of plants to their light environment occurs over generations and at the population level and has resulted in photosynthetic differences among species. 
High-light-adapted species generally have greater photosynthetic capacity; i.e., a higher maximum photosynthetic rate and a higher light-saturation point than shade-adapted species (Björkman, 1981). By contrast, shade-adapted species tend to reach maximum photosynthetic capacity at much lower light intensity and are more likely to incur damage to the photosynthetic reaction centers under high light [photoinhibition (Demmig-Adams and Adams, 1992)]. Although the photosynthetic responses to $P P F$ have been reported for many species, this information has seldom been used to examine how the supplemental light use efficiency changes with changing $P P F$ and how supplemental lighting can be optimized for different species. van Iersel and Gianino (2017) reported that plants with different photosynthetic capacities responded differently to supplemental light. They simulated the responses of net photosynthesis $\left(A_{\mathrm{n}}\right)$ of two species to supplemental light provided at different ambient $P P F$ and found that the highlight-adapted species Campanula portenschlagiana (with greater photosynthetic capacity) showed pronounced increases in $A_{\mathrm{n}}$ when supplemental light was provided at a relatively high ambient $P P F$ of $250 \mu \mathrm{mol} \cdot \mathrm{m}^{-2} \cdot \mathrm{s}^{-1}$, whereas little increase in $A_{\mathrm{n}}$ was observed in the low-light-adapted plant Heuchera americana when supplemental light was provided at the same ambient $P P F$ (van Iersel and Gianino, 2017).

In addition to adaptation, short-term acclimation to light, typically taking place within minutes to weeks (within the life cycle of a plant), can also induce phenotypic modifications that alter plants' photosynthetic light use efficiency (Anderson et al., 1995; Björkman, 1981; Valladares and Niinemets, 2008). Such modifications include changes in leaf anatomical structures (Evans and Poorter, 2001; McMillen and McClendon, 1983), chlorophyll content and chlorophyll a/b ratio (Givnish, 1988; Niinemets, 2010), changes in electron transport capacity per unit chlorophyll (Anderson and Osmond, 1987), rubisco content and activity (Björkman, 1981; Seemann, 1989), xanthophyll cycle pigment pool size (involved in heat dissipation of the absorbed light) (Demmig-Adams and Adams, 1992; Logan et al., 1998), and maximum photosynthetic capacity (Oguchi et al., 2005). The importance of acclimation to different light levels for the efficiency with which plants use supplemental light for photochemistry has not been studied.

Currently, supplemental lighting in greenhouses is typically controlled by a timer or based on ambient light levels. The ability of a crop to efficiently use the supplemental light for photosynthesis is seldom considered when developing supplemental lighting strategies. Few studies have investigated the feasibility of optimizing supplemental lighting in controlled environments based on plant physiological responses to light (van Iersel et al., 2016a, 2016b) and there is a need for information on how supplemental lighting can be optimized for crops adapted and/or acclimated to different light environments. Chlorophyll fluorescence measurements are especially well-suited for this purpose because they can be used to determine how efficiently plants use the provided light in a real-time, noninvasive manner. Therefore, our objectives were the following: 1) to determine the photochemical responses of different species to a wide range of light intensities; 2 ) to quantify how light acclimation affects crops' photochemistry; and 3) to examine how supplemental light use efficiency changes with changing ambient light levels, and how supplemental light can be optimized for crops adapted and/or acclimated to different light environments.

\section{Materials and Methods}

\section{Plant material and growing conditions}

Sweetpotato 'Desana Lime' stem cuttings were rooted in 1.7-L round, plastic containers filled with a soilless substrate [80\% peat: $20 \%$ perlite (v/v) (Fafard 1P; Sun Gro Horticulture, Agawam, MA)]. Lettuce 'Green Ice' was grown from seeds in the same containers and substrate. Young pothos plants were pruned to a few newly formed shoots and then transplanted using the same containers and substrate. Sweetpotato was rooted on a shaded mist bench, and lettuce and pothos were hand-watered in a glass-covered greenhouse for 2 weeks to get them established. After that, all the plants were placed on ebband-flow benches inside a glass-covered greenhouse and subirrigated daily with a nutrient solution containing $100 \mathrm{mg} \cdot \mathrm{L}^{-1} \mathrm{~N}$ made with a water-soluble fertilizer $[15 \mathrm{~N}-2.2 \mathrm{P}-12.45 \mathrm{~K}(15-$ 5-15 Cal-Mag; Everris, Marysville, $\mathrm{OH})]$. During the growing period (20 Mar. to 5 May 2014), the average greenhouse temperature and vapor pressure deficit were (mean $\pm \mathrm{SD}$ ) $21.2 \pm 1.5^{\circ} \mathrm{C}$ and $1.3 \pm 0.3 \mathrm{kPa}$.

\section{Shading treatments}

The ebb-and-flow benches were not covered (full sun), covered with a single layer of commercial $30 \%$ shadecloth, or with a single layer of commercial $70 \%$ shadecloth on all sides of polyvinyl chloride structures installed on top of the benches. Six plants per species were randomly placed on each bench and grown inside the shading structures or in full sun. Quantum sensors (SQ-110; Apogee Instruments, Logan, UT) connected to a data logger (EM50; Decagon Devices, Pullman, WA) were placed on top of each bench at plant height and monitored the $P P F$ every minute. Daily maximum and average $P P F$ and DLI of all three shading treatments were obtained from the light measurements. Compared with the full sun treatment, the average $P P F$ in the treatments that received commercial $30 \%$ and $70 \%$ shadecloth was reduced by $44 \%$ and $75 \%$, respectively. The shading treatments are thus referred to as full sun, $44 \%$ shade, and $75 \%$ shade. The maximum PPF plants experienced over the entire growing period was 1942, 1508, and $665 \mu \mathrm{mol} \cdot \mathrm{m}^{-2} \cdot \mathrm{s}^{-1}$ in the full sun, $44 \%$ shade, and $75 \%$ shade treatment, respectively. Average DLI was (mean \pm SD) $28.7 \pm 10.7$, $16 \pm 5.9$, and $7.0 \pm 2.6 \mathrm{~mol} \cdot \mathrm{m}^{-2} \cdot \mathrm{d}^{-1}$ in the three treatments.

Leaf chlorophyll content index, a relative and unitless value that is nonlinearly related to leaf chlorophyll content, was measured using a chlorophyll meter (CCM-200 plus; Apogee Instruments) on upper-most fully expanded leaves after plants had acclimated to their different light environments for 4 weeks. The measured leaves developed under the different shading treatments.

\section{Light response of chlorophyll fluorescence}

LED LIGHT. After 4 weeks of light acclimation, light response curves of chlorophyll fluorescence were taken under LED light inside a growth chamber (E15; Conviron, Winnipeg, Canada). A custom-built, dimmable 400-W LED unit, consisting of four $100-\mathrm{W}$, warm white LED modules $(3000 \mathrm{~K}$; EpiLEDs, Tainan, Taiwan), capable of providing a PPF of 0 to $2000 \mu \mathrm{mol} \cdot \mathrm{m}^{-2} \cdot \mathrm{s}^{-1}$, was mounted on aluminum heat sinks with cooling fans installed on top of the heat sinks. The spectral distribution of the LEDs was measured using a spectrometer (UniSpec; PP Systems, Amesbury, MA). The LED light had a primary peak at $578 \mathrm{~nm}$ and a secondary peak at $444 \mathrm{~nm}$. 
About $98.5 \%$ of its total photons were within the $400-700 \mathrm{~nm}$ wavelength range, and the other $1.5 \%$ of photons were $>700 \mathrm{~nm}$.

Chlorophyll Fluorescence measurements. Chlorophyll fluorescence was measured on upper-most fully expanded leaves that developed under the different shading treatments. Data were collected using a pulse-amplitude modulated fluorometer (Mini-PAM; Heinz Walz, Effeltrich, Germany). One plant per species from each shading level (three species $\times$ three shading levels; nine plants in total) were randomly placed inside the growth chamber the night before data collection to dark-adapt the plants. Minimum and maximum fluorescence yield of dark-adapted leaves ( $F_{0}$ and $F_{\mathrm{m}}$, respectively) were determined to calculate the ratio of variable to maximum fluorescence $\left(F_{\mathrm{v}} / F_{\mathrm{m}}\right)$, the maximum quantum yield of PSII for photochemistry when all reaction centers are "open" (i.e., oxidized), where $F_{\mathrm{v}}=F_{\mathrm{m}}-F_{0}$. Then, LEDs were switched on at a low light intensity $\left(<20 \mu \mathrm{mol} \cdot \mathrm{m}^{-2} \cdot \mathrm{s}^{-1}\right)$. Plants were given 15-20 min for photosynthesis to stabilize under the light level before steady-state and maximum fluorescence in the light $\left(F_{\mathrm{t}}\right.$ and $F_{\mathrm{m}}{ }^{\prime}$, respectively) were determined. Quantum yield of PSII of light-adapted leaves was calculated as $\Phi_{\mathrm{PSII}}=\left(F_{\mathrm{m}}{ }^{\prime}-F_{\mathrm{t}}\right) / \mathrm{F}_{\mathrm{m}}{ }^{\prime}$ (Genty et al., 1989). During the photochemical reactions, the excitation energy from some of the absorbed photons is used by the reaction center of PSII to transport electrons. This electron transport ultimately leads to the production of adenosine triphosphate (ATP) and ferredoxin, the energy and reducing power that are subsequently used for carbon fixation. The ETR was calculated using the following equation: ETR $=\Phi_{\text {PSII }} \times P P F \times$ $0.84 \times 0.5$ (Baker et al., 2007), where $P P F$ is the incident light intensity at the site of leaf fluorescence measurements and was measured using a quantum sensor embedded in the leaf-clip (2030-B; Heinz Walz) of the fluorometer. This quantum sensor was calibrated under the LED light against a second quantum sensor (LI-190; LI-COR, Lincoln, NE). This estimation of ETR was based on the common assumptions that $84 \%$ of the incident $P P F$ was absorbed by the leaves (Björkman and Demmig, 1987) and that the absorbed $P P F$ was equally partitioned between photosystem I (PSI) and PSII (Baker, 2008; Maxwell and Johnson, 2000). Nonphotochemical quenching, which provides an index of the amount of absorbed light that is dissipated as heat, was calculated as NPQ $=\left(F_{\mathrm{m}}-F_{\mathrm{m}}{ }^{\prime}\right) / F_{\mathrm{m}}{ }^{\prime}$ (Maxwell and Johnson, 2000).

The $P P F$ inside the growth chamber, monitored by a quantum sensor (LI-190, LI-COR) connected to a datalogger (CR1000; Campbell Scientific, Logan, UT) placed in the middle of the growth chamber at plant height, was increased stepwise to a $P P F$ of $\approx 1800 \mu \mathrm{mol} \cdot \mathrm{m}^{-2} \cdot \mathrm{s}^{-1}$ over a period of about $12 \mathrm{~h}$. Light intensity was increased by $\approx 10-150 \mu \mathrm{mol} \cdot \mathrm{m}^{-2} \cdot \mathrm{s}^{-1}$ during each increase, with small increments when $P P F$ was low and then gradually bigger adjustments as $P P F$ increased. Plants were given 15-20 min under each $P P F$ level, and $\Phi_{\text {PSII }}$, ETR, and NPQ at each $P P F$ were determined in a similar manner as described above until the highest $P P F$ of $\pm 1800 \mu \mathrm{mol} \cdot \mathrm{m}^{-2} \cdot \mathrm{s}^{-1}$ was reached. This entire procedure was replicated six times using six sets of plants on $6 \mathrm{~d}$ (each day was treated as a block).

The $P P F$ inside the growth chamber was not uniform, with higher light intensity in the middle than toward the sides of the growth chamber. The $P P F$ at the site of leaf fluorescence measurements thus varied substantially from plant to plant. As plants were randomly placed inside the growth chamber each day, several treatments (i.e., species and shading level combinations) only had one or a few data points at high light intensities $\left(P P F>1000 \mu \mathrm{mol} \cdot \mathrm{m}^{-2} \cdot \mathrm{s}^{-1}\right)$ across all six replications.
In such cases, those data points at high light levels were highly influential in subsequent curve-fitting and could potentially introduce bias in the analyses and were thus excluded from the data analysis.

\section{Experimental design and statistical analysis}

The experimental design was a factorial ( 3 species $\times 3$ shading levels) carried out in a randomized complete block design with six blocks. Data were analyzed using regression (linear, exponential rise to maximum, and exponential decay to minimum) and two-way analysis of variance (ANOVA) in SAS (version 9.2; SAS Institute, Cary, NC). For $\Phi_{\text {PSII }}$, ETR, and NPQ, the light response curve obtained from each plant (i.e., one replicate of a species $\times$ shading level combination) was separately fitted using regression. Initial slopes of the $\Phi_{\mathrm{PSI}}-P P F$, ETR $-P P F$, and NPQ- $P P F$ curves, which estimate the rates of change in $\Phi_{\text {PSII }}$, ETR, and NPQ when a plant is transferred from dark to low light, were derived from the corresponding light response curves fitted through data obtained from each plant. Predicted $\Phi_{\text {PSII }}$, ETR, and NPQ at a $P P F$ of $500 \mu \mathrm{mol} \cdot \mathrm{m}^{-2} \cdot \mathrm{s}^{-1}$ were derived from the fitted regression functions. The initial slopes of the curves and predicted $\Phi_{\mathrm{PSI}}, \mathrm{ETR}$, and NPQ at $P P F$ of $500 \mu \mathrm{mol} \cdot \mathrm{m}^{-2} \cdot \mathrm{s}^{-1}$ were then analyzed using ANOVA with $P$ $<0.05$ considered to be statistically significant. The ETR $-P P F$ curves were also used to estimate the increase in ETR that can be achieved by providing supplemental light $\left(50-250 \mu \mathrm{mol} \cdot \mathrm{m}^{-2} \cdot \mathrm{s}^{-1}\right)$ to different levels of ambient PPF $\left(0-500 \mu \mathrm{mol} \cdot \mathrm{m}^{-2} \cdot \mathrm{s}^{-1}\right)$. This increase in ETR was calculated as the difference between the ETR at a particular ambient $P P F$ and the ETR at that same ambient $P P F$ plus a certain amount of supplemental $P P F$.

\section{Results and Discussion}

Chlorophyll CONTENT AND Plant MORPhology. The leaf chlorophyll content index of the shade-adapted species pothos was $25.5 \pm 1.2$ (mean $\pm \mathrm{SD})$, which was higher than that of light intermediate lettuce $(8.4 \pm 0.8$; mean $\pm \mathrm{SD})$ and high-lightadapted sweetpotato $(3.5 \pm 0.2 ;$ mean $\pm \mathrm{SD})$. Shade-adapted species typically have high leaf chlorophyll content compared with high light plants, a trait that maximizes light capture (Valladares and Niinemets, 2008). Plants not only inherit adaptive traits that developed over generations to optimize fitness under a certain light condition, but also show morphological and physiological acclimation in response to their light environment (Anderson et al., 1995; Björkman, 1981; Valladares and Niinemets, 2008), which vary both over time and within the plant canopy. Many plants have increased leaf chlorophyll content to increase light capture when grown under shade (Evans and Poorter, 2001; Givnish, 1988; Nemali and van Iersel, 2004; Niinemets, 2010), although this response is species-dependent (Logan et al., 1998; Murchie and Horton, 1997). The chlorophyll content index of the three species was not significantly affected by acclimation to different shade levels $(P=0.62$, data not shown).

Morphological modifications in response to light were not the focus of this study and were thus not quantified. However, we did observe that lettuce grown under shade (especially 75\% shade) had pronounced stem elongation, and the leaves of shade-grown pothos tended to be less variegated.

DARK-ADAPTED $\boldsymbol{F}_{\mathrm{V}} / \boldsymbol{F}_{\mathrm{M}}$. Maximum quantum yield of PSII for photochemistry $\left(F_{\mathrm{v}} / F_{\mathrm{m}}\right)$ of plants that had been dark-adapted was significantly affected by the interaction between species 
and light acclimation under different shading levels (Fig. 1). Specifically, $F_{\mathrm{v}} / F_{\mathrm{m}}$ of sweetpotato did not differ among the three shading levels; $F_{\mathrm{v}} / F_{\mathrm{m}}$ of lettuce, however, was lower in the two shaded treatments compared with that in the full sun treatment (Fig. 1). Pothos showed the opposite trend from lettuce: $F_{\mathrm{v}} / F_{\mathrm{m}}$ was highest in plants grown under $75 \%$ shade and lowest in plants grown under full sun (Fig. 1), likely due to photoinhibition (i.e., damage to PSII) by excess light under full sun condition. The PSII reaction center $\mathrm{D}_{1}$ protein degrades during photoinhibition, and the repair of damaged $\mathrm{D}_{1}$ protein is slow (takes hours), causing a fraction of the PSII reaction centers to be nonfunctional, which decreases $F_{\mathrm{v}} / F_{\mathrm{m}}$ (Ruban, 2015). Low-light-grown plants have been reported to have a slower rate of $\mathrm{D}_{1}$ protein turnover (i.e., slower repair cycle of photodamaged PSII reaction centers) (Aro et al., 1993) and a lower capacity for xanthophyll cycle-mediated thermal dissipation of excess absorbed light (Demmig-Adams and Adams, 1992), and thus are often more susceptible to photoinhibition. Alternatively, a reduction in $F_{\mathrm{v}} / F_{\mathrm{m}}$ could be the result of the sustention of high level of xanthophyll cycle pigment zeaxanthin, and consequently sustained thermal dissipation of the absorbed light (which corresponds to lower $\left.\Phi_{\mathrm{PSII}}\right)$, in response to chronic stresses such as excess light and cold (Demmig-Adams and Adams, 2006; Demmig-Adams et al., 2012).

The reduction in $F_{\mathrm{v}} / F_{\mathrm{m}}$ of lettuce grown under shade, however, was unexpected because it is less likely for photoinhibition or sustained thermal dissipation to occur under lower light conditions. The maximum $\Phi_{\mathrm{PSII}}$ estimated from the $\Phi_{\mathrm{PSII}}-P P F$ curves [i.e., the $\Phi_{\mathrm{PSII}}$ at $P P F=0 \mu \mathrm{mol} \cdot \mathrm{m}^{-2} \cdot \mathrm{s}^{-1}$; see section "quantum yield of photosystem II ( $\left.\Phi_{\text {PSII }}\right)$ " below for more details], however, did not differ among the three light acclimation treatments for lettuce, even though it is essentially the same as $F_{\mathrm{v}} / F_{\mathrm{m}}$. For pothos, $F_{\mathrm{v}} / F_{\mathrm{m}}$ and $\Phi_{\mathrm{PSII}}$ at $P P F=0 \mu \mathrm{mol} \cdot \mathrm{m}^{-2} \cdot \mathrm{s}^{-1}$ provided consistent results (data not shown). Therefore, we suspect that the observed reduction in $F_{\mathrm{v}} / F_{\mathrm{m}}$ of lettuce grown under shade might be a measurement artifact.

At all shading levels, sweetpotato consistently had higher $F_{\mathrm{v}} / F_{\mathrm{m}}$ than pothos (Fig. 1), indicating that sweetpotato had a greater capacity for using the absorbed light for photochemistry, when all the PSII reaction centers are "open," than pothos. A high capacity for photochemistry, and a high-lightsaturated maximum photosynthetic rate that is often observed in high light plants (Björkman, 1981), allows high-light-adapted plants like sweetpotato to use high light more efficiently for photosynthesis and reduces the risk of photoinhibition.

QUANTUM YIELD OF PHOTOSYSTEM II $\left(\Phi_{\text {PSII }}\right)$. Quantum yield of PSII of all three species was greatest in the dark and decreased exponentially as $P P F$ increased (Fig. 2A-C). This decrease in $\Phi_{\text {PSII }}$ with increasing $P P F$ level is commonly observed as a greater fraction of PSII reaction centers become "closed" (photo-reduced) under higher light, and are thus unable to use the absorbed light for photochemistry (Baker, 2008; Maxwell and Johnson, 2000).

The rate at which $\Phi_{\text {PSII }}$ decreased with increasing $P P F$ differed among species and among shading levels: within a species, plants grown under heavier shade tended to have more rapid decrease in $\Phi_{\mathrm{PSII}}$ (i.e., photochemistry became less efficient more quickly as $P P F$ increased); and within a shading level, $\Phi_{\mathrm{PSII}}$ tended to decrease fastest in pothos and slowest in sweetpotato as $P P F$ increased (Fig. 2A-C). Specifically, the initial slope of the $\Phi_{\mathrm{PSII}}-P P F$ curve, which is an indicator of

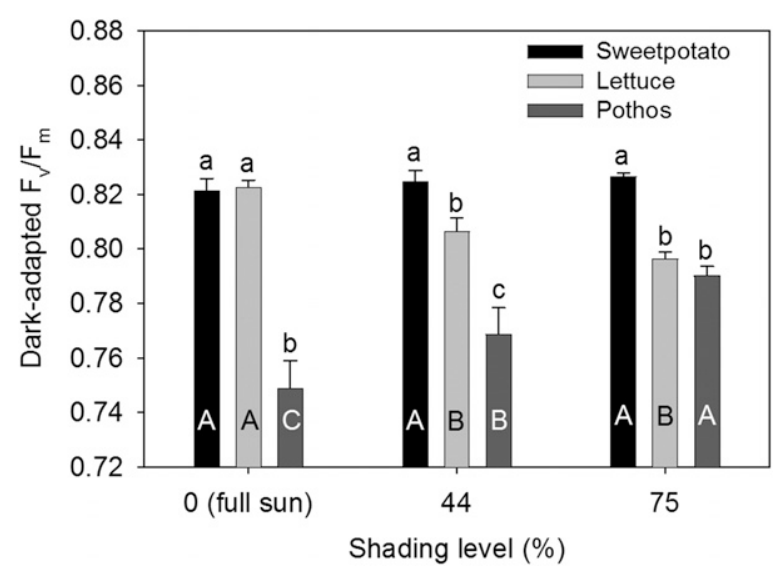

Fig. 1. Dark-adapted $F_{\mathrm{v}} / F_{\mathrm{m}}$ of sweetpotato, lettuce and pothos at three shading levels. Within each species, different uppercase letters indicate significance at $P<0.05$ among the shading levels $(n=6)$. Within each shading level, different lowercase letters indicate significance at $P<0.05$ among the species. Error bars represent SE $(n=6)$

how fast $\Phi_{\mathrm{PSII}}$ decreased when a plant is transferred from dark to low $P P F$, was steeper (i.e., decreased faster) for pothos (Fig. $3 \mathrm{~A}$ ) as well as for plants grown under $75 \%$ shade (Fig. 3B).

To further illustrate how the efficiency at which a plant used the absorbed light for photochemistry varied among species and was affected by acclimation to different shade levels, $\Phi_{\text {PSII }}$ at a $P P F$ of $500 \mu \mathrm{mol} \cdot \mathrm{m}^{-2} \cdot \mathrm{s}^{-1}$, obtained from the fitted $\Phi_{\mathrm{PSII}}-P P F$ curves, was compared among species and among shading levels (note that there was no interactive effect). The $\Phi_{\mathrm{PSII}}$ of sweetpotato at $P P F$ of $500 \mu \mathrm{mol} \cdot \mathrm{m}^{-2} \cdot \mathrm{s}^{-1}$ was $11 \%$ and $81 \%$ higher than that of lettuce and pothos, respectively, indicating that sweetpotato was able to use high light most efficiently, while pothos was least efficient (Fig. 3C). In addition, $\Phi_{\mathrm{PSII}}$ at a $P P F$ of $500 \mu \mathrm{mol} \cdot \mathrm{m}^{-2} \cdot \mathrm{s}^{-1}$ was highest for plants grown under full sun and lowest for plants grown under $75 \%$ shade (Fig. 3D), indicating that plants acclimated to a shade environment were not able to use high light as efficiently as plants that had acclimated to a full sun environment.

Electron tRANSPORT RATE. In contrast to the decrease in $\Phi_{\text {PSII }}$ in response to increasing $P P F$, ETR through PSII increased asymptotically as $P P F$ increased (Fig. 2D-F). During the light reactions of photosynthesis, the transport of electrons through the electron transport chain results in the production of ATP and ferredoxin that are subsequently used in carbon assimilation (Blankenship, 2014) and other processes requiring energy (ATP) or reducing power (ferredoxin). A higher ETR, which requires a high $P P F$ to achieve, has been shown to closely correspond to a higher rate of carbon assimilation/oxygen evolution, especially in the absent of severe stresses, such as drought, that increase the strength of alternative electron sinks; e.g., photorespiration (Beer et al., 1998; Flexas et al., 1999). However, $\Phi_{\mathrm{PSII}}$ is lower under high $P P F$ [see Fig. $2 \mathrm{~A}-\mathrm{C}$ (Baker, 2008; Demmig-Adams et al., 1996; van Iersel et al., 2016b)], meaning that a high ETR, and correspondingly a high rate of carbon assimilation and plant growth, is achieved at the expense of photochemical efficiency (also see van Iersel et al., 2016b).

Consistent with the higher $\Phi_{\text {PSII }}$ observed in sweetpotato and in plants grown under full sun, ETR at a given $P P F$ tended to be greater for sweetpotato than that for lettuce and pothos; higher ETR was also seen in plants acclimated to full sun 


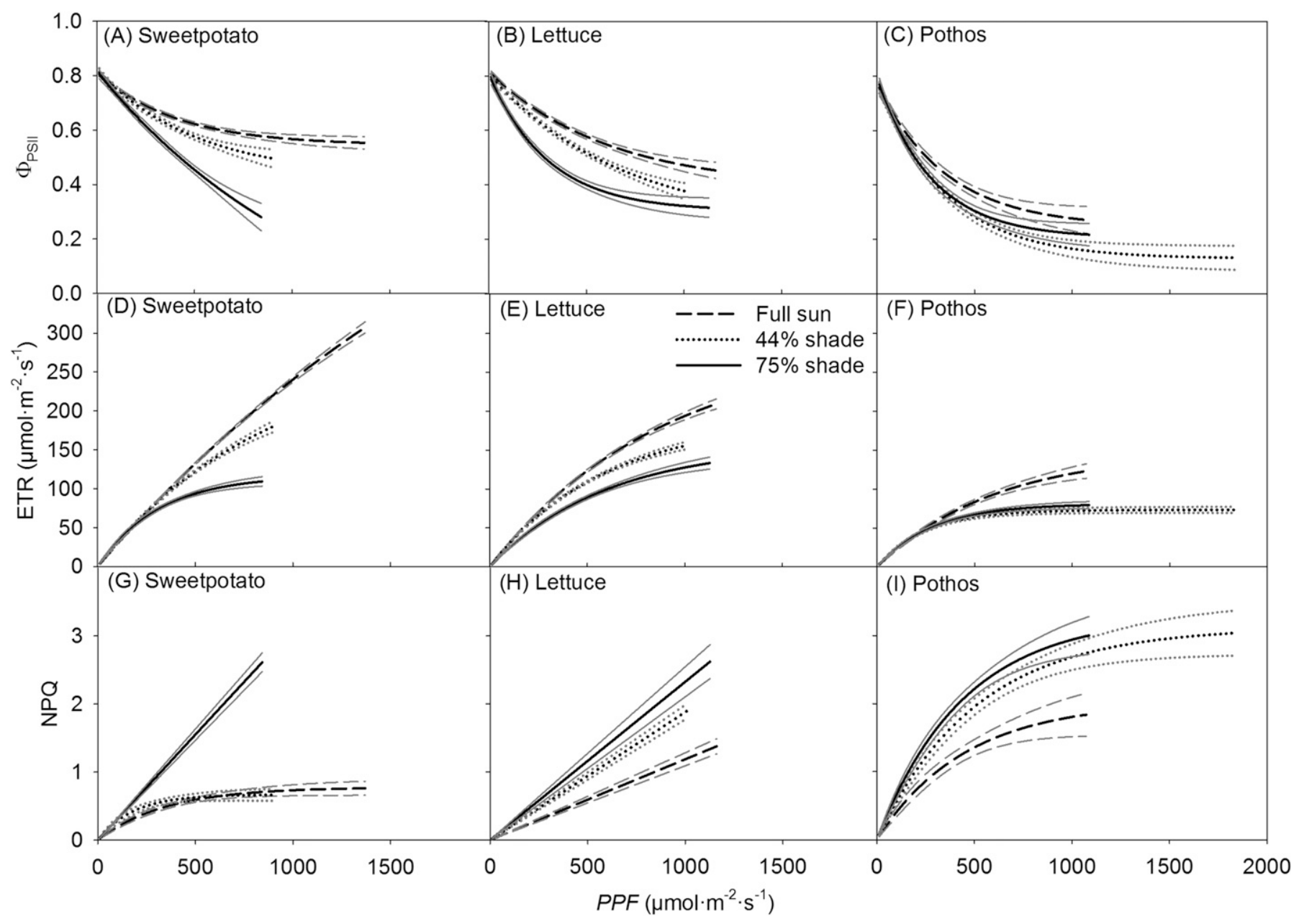

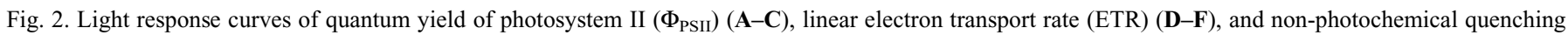
(NPQ) (G-I) for sweetpotato (A, D, G), lettuce $(\mathbf{B}, \mathbf{E}, \mathbf{H})$, and pothos $(\mathbf{C}, \mathbf{F}, \mathbf{I})$ grown under full sun, $44 \%$ shade, and $75 \%$ shade. $P P F$ stands for photosynthetic photon flux. Each regression curve was fitted using data pooled from six replications with gray lines representing the $95 \%$ confidence intervals.

compared with plants grown under shade, especially under high $P P F$ (Fig. 2D-F). Compared with shade-adapted or -acclimated plants, plants adapted or acclimated to high light often have increased electron transport capacities by increasing the content of electron transport components such as cytochrome $\mathrm{f}$ (on per chlorophyll basis), plastoquinone pool, plastocyanin, ferredoxin, and ATP synthase (Anderson and Osmond, 1987; Anderson et al., 1995; Björkman, 1981; Chow et al., 1988; Walters, 2005). Such increases in content of electron transport components; e.g., a bigger plastoquinone pool, allows a greater fraction of reaction centers to be "open" (i.e., oxidized and capable of using excitation energy from light for photochemistry) under a given $P P F$, thus resulting in higher $\Phi_{\text {PSII }}$. In addition, a greater capacity for using the absorbed light for electron transport decreases the need for xanthophyll cyclemediated thermal dissipation, which is discussed in more detail in the section on nonphotochemical quenching below.

The initial slope of the ETR-PPF curve, which gives an estimate of the maximum rate of increase in ETR per unit increase in incident $P P F$, was $15 \%$ higher for sweetpotato than for pothos (Fig. 4A). This is in line with the higher dark-adapted $F_{\mathrm{v}} / F_{\mathrm{m}}$ of sweetpotato compared with that of pothos. Light acclimation to different shading levels, on the other hand, had no effect on the initial slope of the ETR-PPF curve (Fig. 4B).
The ETR of pothos at a $P P F$ of $500 \mu \mathrm{mol} \cdot \mathrm{m}^{-2} \cdot \mathrm{s}^{-1}$ was $40 \%$ and $35 \%$ lower than that of sweetpotato and lettuce, respectively (Fig. 4C), indicating that pothos could not use high light as efficiently for electron transport and, presumably, for subsequent carbon assimilation compared with high-light-adapted plants such as sweetpotato. The ETR at a $P P F$ of $500 \mu \mathrm{mol} \cdot \mathrm{m}^{-2} \cdot \mathrm{s}^{-1}$ also decreased with increasing shading level (Fig. 4D), consistent with the reduction in $\Phi_{\text {PSII }}$ in response to shade acclimation (Fig. 3C and D).

NoN-PHOTOCHEMICAL QUENCHING (NPQ). NPQ of chlorophyll fluorescence, indicative of the degree of change in heat dissipation of the absorbed light relative to that in the darkadapted state (Maxwell and Johnson, 2000), was upregulated as $P P F$ increased (Fig. 2G-I). As NPQ competes with photochemistry for the same excitation energy, a decrease in $\Phi_{\text {PSII }}$ under increasing $P P F$ is often accompanied by an increase in NPQ [see Fig. 2A-C (Demmig-Adams et al., 1996; Matos et al., 2009; van Iersel et al., 2016b)]. This increase in NPQ under high $P P F$ was likely attributable to the upregulation of the xanthophyll cycle-mediated heat dissipation of the excess absorbed energy, a process that is activated by accumulation of $\mathrm{H}^{+}$in the thylakoid lumen (Demmig-Adams and Adams, 1996; Eskling et al., 1997). Accumulation of $\mathrm{H}^{+}$in the lumen in turn results from increasing rates of electron transport as $P P F$ increases 


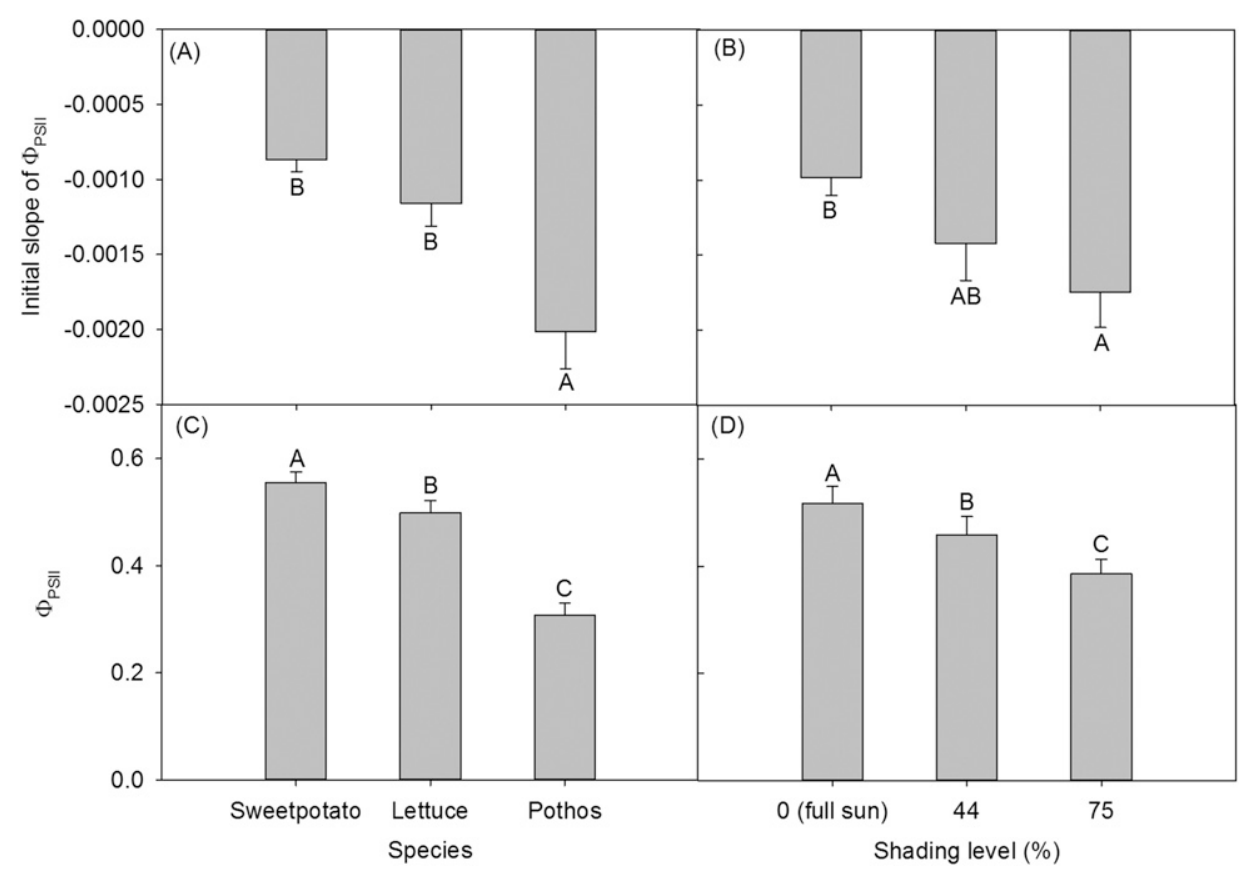

Fig. 3. Initial slope of the quantum yield of photosystem II ( $\left.\Phi_{\text {PSII }}\right)$-photosynthetic photon flux $(P P F)$ curve, an indicator of how fast $\Phi_{\text {PSII }}$ decreased when plant was transferred from dark to light, of sweetpotato, lettuce, and pothos (A) and by shading level (B). Predicted $\Phi_{\text {PSII }}$ at $P P F$ of $500 \mu \mathrm{mol} \cdot \mathrm{m}^{-2} \cdot \mathrm{s}^{-1}$ of sweetpotato, lettuce, and pothos (C) and by shading level (D). There was no significant species $\times$ shading level interaction for both variables. Error bars represent SE $[n=18$ ( 3 species/shading levels $\times 6$ replications)]. Different letters indicate significance at $P<0.05$.

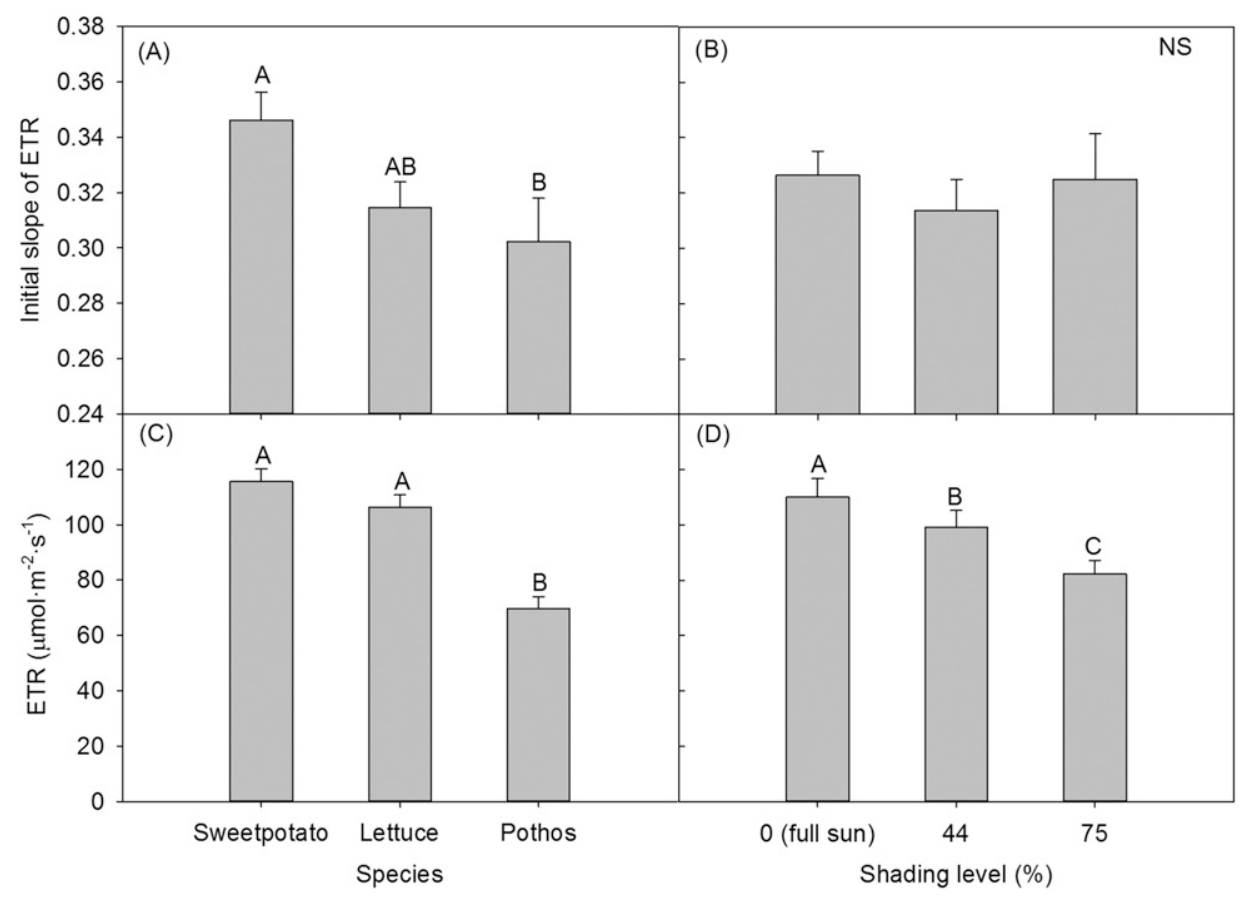

Fig. 4. Initial slope of the electron transport rate (ETR)-photosynthetic photon flux ( $P P F)$ curve, an estimate of the maximum rate of increase in ETR per unit increase in incident $P P F$, of sweetpotato, lettuce, and pothos (A) and by shading level (B). Predicted ETR at $P P F$ of $500 \mu \mathrm{mol} \cdot \mathrm{m}^{-2} \cdot \mathrm{s}^{-1}$ of sweetpotato, lettuce, and pothos (C) and by shading level (D). Error bars represent SE $[n=18$ ( 3 species/shading levels $\times 6$ replications)]. Different letters indicate significance at $P<0.05$. Ns represents nonsignificance.

(Baker et al., 2007; Rochaix, 2014). The xanthophyll cyclemediated heat dissipation contributes to a major part of NPQ and is thought to protect the photosynthetic apparatus from damage (i.e., photoinhibition through damage to PSII, which is another component of NPQ) by safely dissipating the excess light energy as heat (Demmig-Adams and Adams, 1992, 2006).

The need for this photoprotective mechanism varies and depends on 1) the plant's capability of using light for photochemistry and 2) the factors that alter the plant's photosynthetic capacity, including light acclimation and environmental stresses; e.g., excess light, cold, nutrient deficiency, and drought (Demmig-Adams and Adams, 1992; Demmig-Adams et al., 2012; Logan et al., 1998; Verhoeven et al., 1997). It is expected that plants with a low capacity for using light for photosynthesis would have greater need to dissipate excitation energy through alternate pathways; e.g., the xanthophyll cycle. Adams and Demmig-Adams (1992) compared the changes in xanthophyll cycle activity in response to diurnal changes in light intensity between slow-growing species with low photosynthetic capacity and fast growing crops with high photosynthetic capacity. They found that although the slow-growing species had similar or a smaller xanthophyll pool size on a per chlorophyll basis, under high light conditions they converted a much higher fraction of their total xanthophyll pigment pool to zeaxanthin and antheraxathin, the two de-epoxidized forms of xanthophylls that lead to dissipation of excess absorbed light as heat. Maintaining a high fraction of de-epoxidized xanthophylls (i.e., zeaxanthin and antheraxathin) results in faster upregulation of NPQ in response to excess light (Demmig-Adams and Adams, 2006; Demmig-Adams et al., 2012, Logan et al., 1998).

The species differences in the regulation of NPQ are evident in our data: NPQ of pothos increased more quickly on transitioning of plants from dark to light than that of sweetpotato and lettuce, as indicated by the steeper initial slope of the NPQ- $P P F$ curve of pothos (Fig. $5 \mathrm{~A}$ ). In addition, the initial slope of NPQ- $P P F$ was higher in plants grown under $75 \%$ shade than plants grown in full sun and $44 \%$ shade (Fig. 5B), suggesting that acclimation to lower light level also resulted in faster upregulation of heat dissipation 
under increasing light. The NPQ of pothos at a $P P F$ of $500 \mu \mathrm{mol} \cdot \mathrm{m}^{-2} \cdot \mathrm{s}^{-1}$ was twice that of lettuce and sweetpotato (Fig. 5C), indicating greater upregulation of heat dissipation, resulting in lower $\Phi_{\text {PSII }}$ in pothos (see Fig. 3C). NPQ at a $P P F$ of $500 \mu \mathrm{mol} \cdot \mathrm{m}^{-2} \cdot \mathrm{s}^{-1}$ was also higher for plants grown under $75 \%$ shade (Fig. 5C and D), which had lower $\Phi_{\text {PSII }}$ at that light intensity (Fig. 3D).

IMPLICATIONS FOR OPTIMIZING SUPPLEMENTAL LIGHTING. Sweetpotato, lettuce, and pothos showed vast differences in how they used light for photochemistry. In addition, their photosynthetic performance was affected by acclimation to different shade levels. As a result, crop-specific strategies should be used when using supplemental light for different crops; variations in the crop's light use caused by light acclimation should also be taken into account. Although $\Phi_{\text {PSII }}$ decreased with increasing $P P F$ for all three species (Fig. 2A-C), sweetpotato, and lettuce maintained higher $\Phi_{\text {PSII }}$ under high light; i.e., used the provided light more efficiently to drive electron transport. Pothos, on the other hand, had a lower $\Phi_{\text {PSII }}$ at the same $P P F$ and increased NPQ more rapidly with increasing $P P F$. Consequently, for the same amount of supplemental light provided, greater increases in ETR, and presumably in carbon assimilation and growth, can be achieved in sweetpotato and lettuce than in pothos, especially when ambient $P P F$ is high (Fig. 6).

Consistent with the decreases in $\Phi_{\text {PSII }}$ with increasing $P P F$, the increase in ETR per unit $P P F$ supplemented diminishes with increasing light intensity for all species (Fig. 6). However, this diminishing return at higher light levels is most pronounced in pothos: the increase in ETR of pothos that can be achieved by providing the same amount of supplemental light decreased more quickly with increasing ambient $P P F$ compared with that of sweetpotato and lettuce (Fig. 6). For instance, at an ambient $P P F$ of $0 \mu \mathrm{mol} \cdot \mathrm{m}^{-2} \cdot \mathrm{s}^{-1}$ (dark), supplemental light of $250 \mu \mathrm{mol} \cdot \mathrm{m}^{-2} \cdot \mathrm{s}^{-1}$ provided to plants grown under full sun can increase ETR by $68.3 \mu \mathrm{mol} \cdot \mathrm{m}^{-2} \cdot \mathrm{s}^{-1}$ in sweetpotato, $69.2 \mu \mathrm{mol} \cdot \mathrm{m}^{-2} \cdot \mathrm{s}^{-1}$ in lettuce, and $51.2 \mu \mathrm{mol} \cdot \mathrm{m}^{-2} \cdot \mathrm{s}^{-1}$ in pothos (Fig. 6A-C). By contrast, same amount of supplemental light provided at an ambient $P P F$ of $500 \mu \mathrm{mol} \cdot \mathrm{m}^{-2} \cdot \mathrm{s}^{-1}$ increases ETR by $55.9 \mu \mathrm{mol} \cdot \mathrm{m}^{-2} \cdot \mathrm{s}^{-1}$ (18\% less compared with that provided at an ambient $P P F$ of $0 \mu \mathrm{mol} \cdot \mathrm{m}^{-2} \cdot \mathrm{s}^{-1}$ ) in

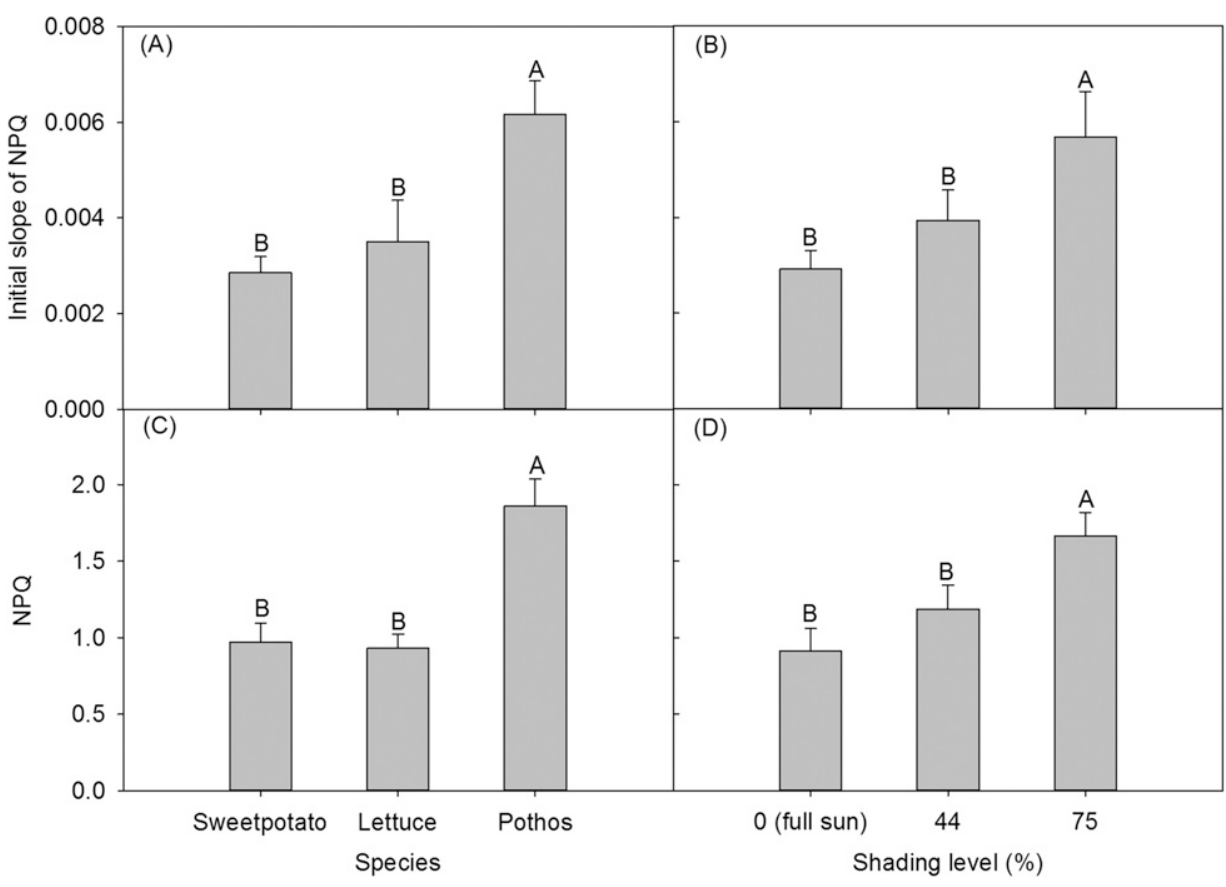

Fig. 5. Initial slope of the non-photochemical quenching (NPQ)-photosynthetic photon flux $(P P F)$ curve, which is indicative of the rate of increase in heat dissipation of the absorbed light upon transfer of plants from dark to light, of sweetpotato, lettuce, and pothos (A) and by shading level (B). Predicted NPQ at $P P F$ of $500 \mu \mathrm{mol} \cdot \mathrm{m}^{-2} \cdot \mathrm{s}^{-1}$ of sweetpotato, lettuce, and pothos (C) and by shading level (D). Error bars represent SE [ $n=18$ ( 3 species/shading levels $\times 6$ replications)]. Different letters indicate significance at $P<0.05$.

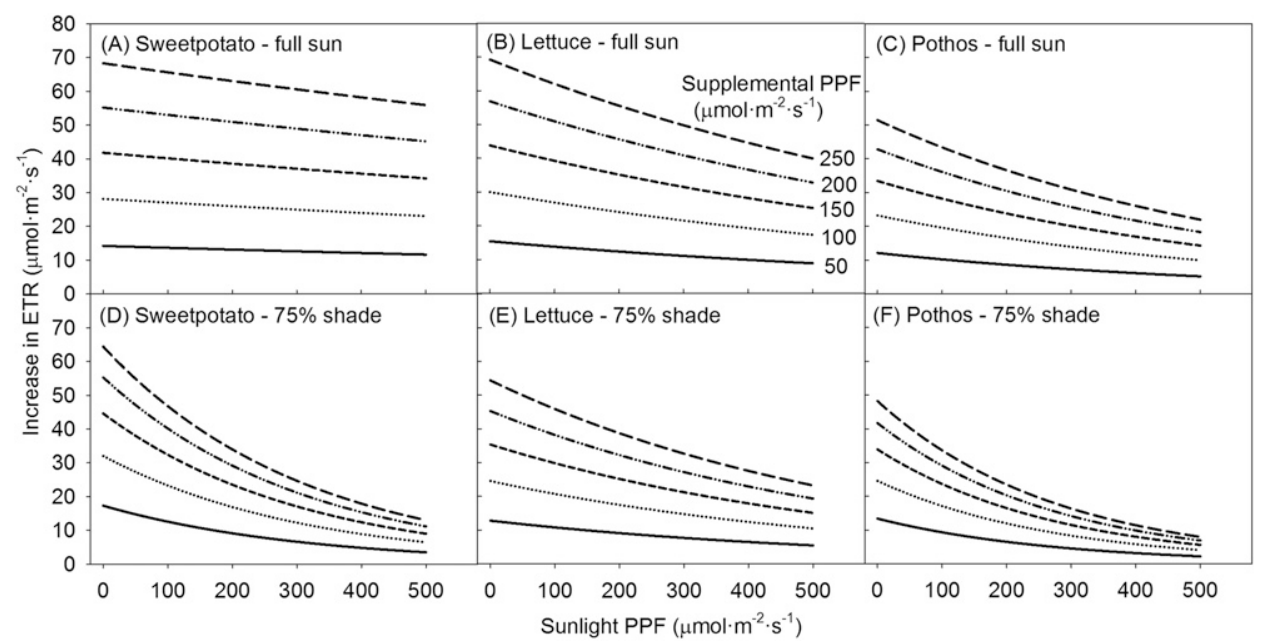

Fig. 6. The estimated increase in electron transport rate (ETR) that can be achieved by providing supplemental light of $50-250 \mu \mathrm{mol} \cdot \mathrm{m}^{-2} \cdot \mathrm{s}^{-1}$ to different intensities of ambient (sunlight) photosynthetic photon flux (PPF). The curves for sweetpotato $(\mathbf{A}, \mathbf{D})$, lettuce $(\mathbf{B}, \mathbf{E})$, and pothos $(\mathbf{C}, \mathbf{F})$ grown under full sun $(\mathbf{A}-\mathbf{C})$ and $75 \%$ shade
(D and $\mathbf{E})$ were derived from the corresponding light response curves of ETR as shown in Fig. 2D-F.

sweetpotato, $39.9 \mu \mathrm{mol} \cdot \mathrm{m}^{-2} \cdot \mathrm{s}^{-1}$ (42\% less) in lettuce, and only $22.0 \mu \mathrm{mol} \cdot \mathrm{m}^{-2} \cdot \mathrm{s}^{-1}(57 \%$ less) in pothos (Fig. $6 \mathrm{~A}-\mathrm{C}$ ). It is thus most beneficial to provide supplemental light to pothos when ambient $P P F$ is low. By contrast, supplemental light provided at high ambient $P P F$ can be used with relatively high efficiency to further increase ETR of sweetpotato and lettuce. The simulation of the responses of net photosynthesis $\left(A_{\mathrm{n}}\right)$ of two species to supplemental light by van Iersel and Gianino (2017) similarly showed that same amount of supplemental light can result in less increase in $A_{\mathrm{n}}$ when provided at higher 
ambient $P P F$. They also found that the increase in $A_{\mathrm{n}}$ from providing supplemental light at relatively high ambient $P P F$ was much greater in the high-light-adapted species $C$. portenschlagiana than in the low-light-adapted species $H$. americana (van Iersel and Gianino, 2017).

The simulation by van Iersel and Gianino (2017) did not account for the effects of light acclimation on a crop's photosynthetic performance. As shown by our data, light acclimation significantly affected the light responses of $\Phi_{\text {PSII }}$, ETR, and NPQ and thus must be taken into consideration when developing lighting strategy for a specific crop. Compared with shade-acclimated plants, high-light-grown plants of all three species were able to maintain higher $\Phi_{\mathrm{PSI}}$ at high $P P F$ and had greater ETR and slower upregulation of NPQ (i.e., heat dissipation), thereby could use supplemental light more efficiently for photosynthesis when provided at high ambient $P P F$. Supplemental light of $250 \mu \mathrm{mol} \cdot \mathrm{m}^{-2} \cdot \mathrm{s}^{-1}$ provided at ambient $P P F$ of $500 \mu \mathrm{mol} \cdot \mathrm{m}^{-2} \cdot \mathrm{s}^{-1}$ can increase the ETR of sweetpotato grown under full sun by $55.9 \mu \mathrm{mol} \cdot \mathrm{m}^{-2} \cdot \mathrm{s}^{-1}$ compared with an increase in ETR of only $13 \mu \mathrm{mol} \cdot \mathrm{m}^{-2} \cdot \mathrm{s}^{-1}$ in sweetpotato grown under $75 \%$ shade (Fig. 6A and D). Similarly, providing $250 \mu \mathrm{mol} \cdot \mathrm{m}^{-2} \cdot \mathrm{s}^{-1}$ of supplemental light to an ambient PPF of $500 \mu \mathrm{mol} \cdot \mathrm{m}^{-2} \cdot \mathrm{s}^{-1}$ can increase ETR of lettuce grown under full sun and $75 \%$ shade by 39.9 and $23.2 \mu \mathrm{mol} \cdot \mathrm{m}^{-2} \cdot \mathrm{s}^{-1}$, respectively (Fig. 6B and E). The ETR of pothos grown under full sun and $75 \%$ shade can increase by 22 and $7.9 \mu \mathrm{mol} \cdot \mathrm{m}^{-2} \cdot \mathrm{s}^{-1}$, respectively, when plants are provided with $250 \mu \mathrm{mol} \cdot \mathrm{m}^{-2} \cdot \mathrm{s}^{-1}$ of supplemental $P P F$ at an ambient $P P F$ of $500 \mu \mathrm{mol} \cdot \mathrm{m}^{-2} \cdot \mathrm{s}^{-1}$ (Fig. $6 \mathrm{C}$ and $\mathrm{F})$. To get the maximum benefit from supplemental light, it is important that the plants are acclimated to relatively high light. Providing supplemental light to a crop that was previously grown under low light conditions is likely to be relatively ineffective because the shade-acclimated crop will not be able to use that light efficiently. Nonetheless, supplemental light is often provided to plants that grow under, thus are acclimated to, low light conditions (e.g., during winter months). In such cases, the efficiency with which plants use the provided light for photochemistry may increase as plants acclimate to the higher light level provided by the supplemental light. Thus, supplemental light may not simply increase instantaneous photosynthesis but also lead to acclimation that enables the plants to use supplemental light more efficiently. The ability of plants to acclimate and how quickly this occurs may differ among species (Figs. 2 and 6).

The light response curves of $\Phi_{\text {PSII }}$ and ETR obtained using chlorophyll fluorescence measurements provide important quantitative information on how efficiently various crops use the provided light for photosynthesis and how their responses are affected by light acclimation. Given the relative simplicity of the measurements, chlorophyll fluorescence can be used as an effective tool to optimize crop-specific lighting strategies (van Iersel et al., 2016a).

\section{Conclusions}

High PPF is needed to achieve high ETR and presumably a high rate of photosynthesis and growth. However, $\Phi_{\text {PSII }}$ and the increase in ETR that can be achieved with each unit increase in supplemental light decrease with increasing ambient $P P F$, suggesting that supplemental lighting is used less efficiently for photochemistry when provided at high ambient $P P F$. The photosynthetic responses differ among species and are affected by light acclimation, with high-light-adapted species and plants acclimated to a high light environment being more efficient in using light for electron transport than low light adapted/ acclimated plants. Supplemental lighting strategies thus should be species-specific and take account of the effect of light acclimation.

\section{Literature Cited}

Adams, W.W., III, and B. Demmig-Adams. 1992. Operation of the xanthophyll cycle in higher plants in response to diurnal changes in incident sunlight. Planta 186:390-398.

Anderson, J.M., W.S. Chow, and Y. Park. 1995. The grand design of photosynthesis: Acclimation of the photosynthetic apparatus to environmental cues. Photosynth. Res. 46:129-139.

Anderson, J.M. and C.B. Osmond. 1987. Shade - sun responses: Compromises between acclimation and photoinhibition, p. 1-36. In: D.J. Kyle, C.B. Osmond, and C.J. Arntzen (eds.). Photoinhibition. Elsevier Science, Amsterdam, The Netherlands.

Aro, E., S. McCaffery, and J.M. Anderson. 1993. Photoinhibition and D1 protein degradation in peas acclimated to different growth irradiances. Plant Physiol. 103:835-843.

Baker, N.R. 2008. Chlorophyll fluorescence: A probe of photosynthesis in vivo. Annu. Rev. Plant Biol. 59:89-113.

Baker, N.R., J. Harbinson, and D.M. Kramer. 2007. Determining the limitations and regulation of photosynthetic energy transduction in leaves. Plant Cell Environ. 30:1107-1125.

Beer, S., B. Vilenkin, A. Weil, M. Veste, L. Susel, and A. Eshel. 1998. Measuring photosynthetic rates in seagrasses by pulse amplitude modulated (PAM) fluorometry. Mar. Ecol. Prog. Ser. 174:293-300.

Björkman, O. 1981. Responses to different quantum flux densities, p. 57-107. In: O.L. Lange, P.S. Nobel, C.B. Osmond, and H. Ziegler (eds.). Physiological plant ecology I. Encyclopedia of plant physiology, Vol. 12A. Springer-Verlag, Berlin, Germany.

Björkman, O. and B. Demmig. 1987. Photon yield of $\mathrm{O}_{2}$ evolution and chlorophyll fluorescence characteristics at $77 \mathrm{k}$ among vascular plants of diverse origins. Planta 170:489-504.

Blankenship, R.E. 2014. Molecular mechanisms of photosynthesis. 2nd ed. Wiley, Oxford, UK.

Chow, W.S., L. Qian, D.J. Goodchild, and J.M. Anderson. 1988. Photosynthetic acclimation of Alocasia macrorrhiza (L.) G. Don to growth irradiance: Structure, function and composition of chloroplasts. Austral. J. Plant Physiol. 15:107-122.

Demmig-Adams, B. and W.W. Adams, III. 1992. Photoprotection and other responses of plants to high light stress. Annu. Rev. Plant Physiol. Plant Mol. Biol. 43:599-626.

Demmig-Adams, B. and W.W. Adams, III. 1996. The role of xanthophyll cycle carotenoids in the protection of photosynthesis. Trends Plant Sci. 1:21-26.

Demmig-Adams, B. and W.W. Adams, III. 2006. Photoprotection in an ecological context: The remarkable complexity of thermal energy dissipation. New Phytol. 172:11-21.

Demmig-Adams, B., W.W. Adams, III, D.H. Barker, B.A. Logan, D.R. Bowling, and A.S. Verhoeven. 1996. Using chlorophyll fluorescence to assess the fraction of absorbed light allocated to thermal dissipation of excess excitation. Physiol. Plant. 98:253-264.

Demmig-Adams, B., C.M. Cohu, O. Muller, and W.W. Adams, III. 2012. Modulation of photosynthetic energy conversion in nature: From seconds to seasons. Photosynth. Res. 113:75-88.

Eskling, M., P. Arvidsson, and H. Ảkerlund. 1997. The xanthophyll cycle, its regulation and components. Physiol. Plant. 100:806-816.

Evans, J.R. and H. Poorter. 2001. Photosynthetic acclimation of plants to growth irradiance: The relative importance of specific leaf area and nitrogen partitioning in maximizing carbon gain. Plant Cell Environ. 24:755-767.

Flexas, J., J.M. Escalona, and H. Medrano. 1999. Water stress induces different levels of photosynthesis and electron transport rate regulation in grapevines. Plant Cell Environ. 22:39-48. 
Gaudreau, L. and J. Chartbonneau. 1994. Photoperiod and photosynthetic photon flux influence growth and quality of greenhouse-grown lettuce. HortScience 29:1285-1289.

Genty, B., J. Briantais, and N.R. Baker. 1989. The relationship between the quantum yield of photosynthetic electron transport and quenching of chlorophyll fluorescence. Biochim. Biophys. Acta 990:87-92.

Givnish, T.J. 1988. Adaptation to sun and shade: A whole-plant perspective. Austral. J. Plant Physiol. 15:63-92.

Korczynski, P.C., J. Logan, and J.E. Faust. 2002. Mapping monthly distribution of daily light integrals across the contiguous United States. HortTechnology 12:12-16.

Logan, B.A., B. Demmig-Adams, W.W. Adams, III, and S.C. Grace. 1998. Antioxidants and xanthophyll cycle-dependent energy dissipation in Cucurbita pepo L. and Vinca major L. acclimated to four growth PPFDs in the field. J. Expt. Bot. 49:1869-1879.

Lopez, R.G. and E. Runkle. 2008. Photosynthetic daily light integral during propagation influences rooting and growth of cuttings and subsequent development of new guinea impatiens and petunia. HortScience 43:2052-2059.

Matos, F.S., R. Wolfgramm, F.V. Gonçalves, P.C. Cavatte, M.C. Ventrella, and F.M. DaMatta. 2009. Phenotypic plasticity in response to light in the coffee tree. Environ. Expt. Bot. 67:421-427.

Maxwell, K. and G.N. Johnson. 2000. Chlorophyll fluorescence - A practical guide. J. Expt. Bot. 51:659-668.

McMillen, G.G. and J.H. McClendon. 1983. Dependence of photosynthetic rates on leaf density thickness in deciduous woody plants grown in sun and shade. Plant Physiol. 72:674-678.

Murchie, E.H. and P. Horton. 1997. Acclimation of photosynthesis to irradiance and spectral quality in British plant species: Chlorophyll content, photosynthetic capacity and habitat preference. Plant Cell Environ. 20:438-448.

Nelson, P.V. 2012. Greenhouse operation and management. 7th ed. Prentice Hall, Upper Saddle River, NJ.

Nelson, J.A. and B. Bugbee. 2014. Economic analysis of greenhouse lighting: Light emitting diodes vs. high intensity discharge fixtures. PLoS One 9(6):e99010.
Nemali, K.S. and M.W. van Iersel. 2004. Acclimation of wax begonia to light intensity: Changes in photosynthesis, respiration, and chlorophyll concentration. J. Amer. Soc. Hort. Sci. 129:745-751.

Niinemets, Ü. 2010. A review of light interception in plant stands from leaf to canopy in different plant functional types and in species with varying shade tolerance. Ecol. Res. 25:693-714.

Oguchi, R., K. Hikosaka, and T. Hirose. 2005. Leaf anatomy as a constraint for photosynthetic acclimation: Differential responses in leaf anatomy to increasing growth irradiance among three deciduous trees. Plant Cell Environ. 28:916-927.

Rochaix, J. 2014. Regulation and dynamics of the light-harvesting system. Annu. Rev. Plant Biol. 65:287-309.

Ruban, A.V. 2015. Evolution under the sun: Optimizing light harvesting in photosynthesis. J. Expt. Bot. 66:7-23.

Seemann, J.R. 1989. Light adaptation/acclimation of photosynthesis and the regulation of ribulose-1,5-bisphosphate carboxylase activity in sun and shade plants. Plant Physiol. 91:379-386.

Valladares, F. and Ü. Niinemets. 2008. Shade tolerance, a key plant feature of complex nature and consequences. Annu. Rev. Ecol. Evol. Syst. 39:237-257.

van Iersel, M.W. and D. Gianino. 2017. An adaptive control approach for LED lights can reduce the energy costs of supplemental lighting in greenhouses. HortScience 52:72-77.

van Iersel, M.W., E. Mattos, G. Weaver, R.S. Ferrarezi, M.T. Martin, and M. Haidekker. 2016a. Using chlorophyll fluorescence to control lighting in controlled environment agriculture. Acta Hort. 1134:427-433.

van Iersel, M.W., G. Weaver, M.T. Martin, R.S. Ferrarezi, E. Mattos, and M. Haidekker. 2016b. A chlorophyll fluorescence-based biofeedback system to control photosynthetic lighting in controlled environment agriculture. J. Amer. Soc. Hort. Sci. 141:169-176.

Verhoeven, A.S., B. Demmig-Adams, and W.W. Adams, III. 1997. Enhanced employment of the xanthophyll cycle and thermal energy dissipation in spinach expose to high light and N stress. Plant Physiol. 113:817-824.

Walters, R.G. 2005. Towards an understanding of photosynthetic acclimation. J. Expt. Bot. 56:435-447. 